\title{
Paget Disease of the Anal Margin
}

National Cancer Institute

\section{Source}

National Cancer Institute. Paget Disease of the Anal Margin. NCI Thesaurus. Code C7476.

Paget disease involving the perianal skin. 